\title{
Ação do estanozolol sobre a histologia renal e hepática em ratos treinados com natação
}

[Stanozolol action on renal and hepatic histology in swimming trained rats]

$$
\text { F.C.S. Lima }{ }^{1} \text {, A.A.C. Teixeira }{ }^{1,2} \text {, S.B. Silva }{ }^{1} \text {, W.E. Silva }{ }^{1} \text {, }
$$
I.M.F. Melo ${ }^{1}$, A.F. Soares ${ }^{1,2 *}$

${ }^{1}$ Programa de pós-graduação - Universidade Federal Rural de Pernambuco - UFRPE - Recife, PE

${ }^{2}$ Universidade Federal Rural de Pernambuco - UFRPE - Recife, PE

\begin{abstract}
RESUMO
No presente estudo, foram analisados os efeitos do estanozolol, associado ou não à atividade física, sobre o hemograma, o peso ponderal, a ingestão líquida e sólida, a urinálise, a expressão do VEGF-A renal e o glicogênio hepático, além da histopatologia hepática e renal em ratos Wistar. Foram utilizados 32 ratos Wistar, machos, jovens, separados em quatro grupos: GC (grupo controle); GCE (grupo controleexercício); GT (grupo tratamento-esteroide); GTE (grupo tratamento-esteroide-exercício). Os animais dos grupos GT e GTE $(n=16)$ foram submetidos a injeções subcutâneas, cinco dias/semana, durante 30 dias, na concentração de $5 \mathrm{mg} / \mathrm{kg}$ de estanozolol diluído em $1 \mathrm{~mL}$ de óleo de gergelim, utilizado como veículo. A natação foi definida como exercício físico. Houve aumento no peso dos animais submetidos ao estanozolol e ao exercício a partir da terceira semana de uso e aumento da excreção urinária a partir da quinta semana; os demais parâmetros da urinálise foram semelhantes entre os grupos. O uso de estanozolol associado ou não à atividade física promoveu redução da expressão do VEGF-A nos rins e do glicogênio hepático, além de alterações histopatológicas nesses órgãos. Quanto à hematologia, houve uma diminuição dos leucócitos no GTE em relação aos grupos GT e GCE. Quanto aos linfócitos, houve um aumento no GT e uma diminuição no GTE, e, em relação ao número de plaquetas, houve diminuição no GTE quando comparado ao GT e ao GCE Assim, conclui-se que estanozolol na dose de 5,0mg/kg causa alterações renais e hepáticas em ratos Wistar, podendo levar à falência dos rins e do fígado.
\end{abstract}

Palavras-chave: anabolizantes, estanozolol, função renal, hepatotoxicidade

\begin{abstract}
The goal of this study was to determine the effect of stanozolol (ST) on kidney and liver of Wistar rats. Thirty-two male animals were divided into the following four groups: control group (CG); Control group-exercise (GCE); Group-steroid treatment (GT); Group treatment-steroid-exercise (GTE). Swimming was defined as exercise. The animals GT and GTE was submitted to subcutaneous injections, five days/week for 30 days, at a concentration of $5 \mathrm{mg} / \mathrm{kg}$ ST diluted in $1 \mathrm{~mL} / \mathrm{kg}$ of sesame oil. The results showed an increase in weight gain in all animals submitted to ST and exercise from the 3rd week of use and increase in urinary excretion from the 5 th week and the other urinalysis parameters were similar. The ST associated or not with physical activity reduced VEGF-A expression in the kidneys and hepatic glycogen, as well as histopathological changes in these organs. Regarding hematology, there was a decrease in leukocytes in the GTE. As for lymphocytes there was an increase in GT and a decrease in GTE, and in relation to the number of platelets, there was a decrease in GTE. In conclusion, the administration of stanozolol at $5.0 \mathrm{mg} / \mathrm{kg}$ caused a structural change of kidney and liver in treated animals.
\end{abstract}

Keywords: anabolic steroids, stanozolol, renal function, liver toxicity

Recebido em 25 de fevereiro de 2019

Aceito em 20 de setembro de 2019

*Autor para correspondência (corresponding author)

E-mail: anisiofsoares@gmail.com 


\section{INTRODUÇÃO}

Esteroides anabólicos androgênicos (EAA) são derivados sintéticos da testosterona (Bahrke e Yesalis, 2004), empregados na medicina há pelo menos cinco décadas, para os quadros de hipogonadismo e deficiência do metabolismo proteico. Além disso, são amplamente utilizados por atletas e não atletas para aumentar o desenvolvimento muscular e a força física. Entretanto, outros efeitos histofisiológicos também são observados, tais como: aumento do número de hemácias, na concentração de hemoglobina e hematócrito, entre outros (Lise et al., 1999. Assim como os endógenos, possuem tanto atividade anabólica como androgênica, sendo essa relação variável de acordo com o tipo de substância utilizada (Cunha, 2004).

Sabe-se que o uso crônico de EAA causa alterações em diversos órgãos, tais com rins e fígado. Vários estudos sugerem que os anabolizantes possam exercer um efeito tóxico direto sobre as células glomerulares, levando ao acúmulo na matriz mesangial, à degeneração dos podócitos e à redução do fator de crescimento vascular endotelial (VEGF) (Tufro, 2000; D’Errico; Di Battista, 2011). No fígado, têm sido associados com a peliose hepática, a icterícia colestática, a redução do glicogênio e os adenomas hepatocelulares (Welder, 1995).

Um dos EAA mais populares é o estanozolol (ST), um derivado androgênico $17 \alpha$-alquilado, que apresenta maior potência anabólica e degradação hepática mais lenta do que o hormônio natural masculino (Bocaline; Beutel, 2014). O ST é permitido para uso zootécnico, no entanto é proibido para fins de engorda para os animais destinados para consumo humano (Tölgyesi; Sharma, 2014). Esse anabolizante é preferido por muitas pessoas pelo fato de causar aumento de força sem ganho de peso em excesso, promover aumento na vascularização, não se converter em estrógeno, não causar retenção de água em excesso, além de ajudar na perda de gordura preservando a massa muscular (Pey et al., 2003). Entretanto, há poucos estudos acerca dos efeitos do ST sobre os rins e o fígado. Dessa forma, este trabalho teve por objetivo avaliar em ratos os impactos causados por esse anabolizante sobre o hemograma, o desenvolvimento ponderal, a morfofisiologia renal (balanço hídrico e expressão do VEGF) e hepática (concentração de glicogênio).

\section{MATERIAL E MÉTODOS}

Foram utilizados 32 ratos Wistar, machos (Rattus norvegicus, var. albinus) de 60 dias, com peso entre $230 \pm 19 \mathrm{~g}$, provenientes do biotério do Departamento de Morfologia e Fisiologia Animal (DMFA) da Universidade Federal Rural de Pernambuco (UFRPE), mantidos em ambiente com temperatura de $22 \pm 5^{\circ} \mathrm{C}$, com ciclos alternados de claro-escuro de 12 horas, em regime de alimentação ad libitum. Este estudo foi aprovado pelo Comitê de Ética no Uso de Animais da UFRPE, sob a licença $n^{\circ}$ 074/2014. Os animais foram distribuídos em quatro grupos $(n=8)$, sendo denominados: GC (grupo controle animais não submetidos a exercício e não tratados com esteroide); GCE (grupo controleexercício - animais submetidos a exercício, mas não tratados com esteroide); GT (grupo tratamento-esteroide - animais não submetidos ao exercício, mas tratados com esteroide); GTE (grupo tratamento-esteroide-exercício - animais submetidos ao exercício e tratados com esteroide). Os animais dos grupos GT e GTE $(n=16)$ foram submetidos a injeções subcutâneas, cinco dias/semana, durante 30 dias, na concentração de $5 \mathrm{mg} / \mathrm{kg}$ de estanozolol diluído em $1 \mathrm{~mL}$ de óleo de gergelim, que foi utilizado como veículo, doses baseadas no modelo de dependência descrito por Breuer et al. (2001). Os animais dos grupos GC e GCE foram submetidos às mesmas condições de administração dos grupos GT e GTE, exceto pela ausência do esteroide no veículo que foi administrado. Uma semana antes do início do tratamento, os animais passaram por um período de adaptação à natação; em seguida, foram submetidos, diariamente, à atividade física de natação por 20 minutos, cinco dias/semana, durante quatro semanas.

O peso dos animais foi mensurado semanalmente a partir do início do tratamento com o esteroide, para avaliação do desenvolvimento ponderal. Para contribuir nos estudos da função renal e do balanço hídrico, foram utilizadas gaiolas metabólicas individuais (GMI) por um período de 24 horas. A água e a ração foram mensuradas separadamente antes e após as 24 horas, e a urina coletada continuamente, tendo seu volume mensurado e cada amostra acondicionada em 
tubos e congelada a $-20^{\circ} \mathrm{C} /-80^{\circ} \mathrm{C}$ para posterior análise. A partir desses dados, o estudo do balanço hidroeletrolítico foi realizado. A ingestão sólida (IS, em g/100g/24h) foi determinada por método gravimétrico, em balança mecânica, onde foi pesada a ração de cada animal, obtendo-se, assim, após 24 horas, o total consumido em 24 horas; a ingestão líquida (IL, em $\mathrm{mL} / 100 \mathrm{~g} / 24 \mathrm{~h}$ ) foi determinada por método volumétrico, sendo medido o volume de água no início e ao fim das 24 horas, para cada animal; a diurese (volume urinário, em $\mathrm{mL} / 100 \mathrm{~g} / 24 \mathrm{~h}$ ) foi coletada continuamente, sendo seu volume determinado por método volumétrico; a densidade urinária de $24 \mathrm{~h}(\mathrm{D}$, em $\mathrm{g} / \mathrm{L}$ ) foi medida em refratômetro; o $\mathrm{pH}$ da urina foi determinado em pHmetro. Para esse protocolo, após as quatro semanas de experimento, cinco animais de cada grupo, GC, GCE, GT e GTE, foram submetidos à eutanásia (sendo um animal de cada grupo eutanasiado por semana); para isso, os animais foram anestesiados por via intramuscular com quetamina $(80 \mathrm{mg} / \mathrm{kg})$ e xilazina $(6 \mathrm{mg} / \mathrm{kg})$ para a remoção total dos rins e do fígado. Os órgãos coletados foram fixados em formol tamponado por 24 horas e processados para inclusão em parafina. Os rins foram submetidos à coloração hematoxilina-eosina (HE) e à imunohistoquímica para o fator de crescimento do endotélio vascular (VEGF-A - Santa Cruz Biotechnology Inc., Santa Cruz, CA, EUA). Os fígados foram corados pela hematoxilina-eosina (HE) e pelo ácido periódico de Schiff (PAS) para histoquímica. O sangue dos animais foi coletado no sétimo, $14^{\circ}, 21^{\circ}$ e $28^{\circ}$ dias de experimento, mediante punção cardíaca, com seringas contendo EDTA, e colocado em microtubos. As imagens foram capturadas por câmera de Vídeo Sony ${ }^{\circledR}$, acoplada ao microscópio Olympus ${ }^{\circledR}$ Bx50, e submetidas ao aplicativo Gimp 2.0 para a quantificação por meio de histograma RGB (Red-Green-Blue) (Oberholzer et al., 1996). Foi empregado o Statistical Program for Social Sciences (SPSS), versão 11.0.1 para Windows, aplicados testes não paramétricos de KruscalWallis, e as médias comparadas pelo teste de Wilcoxon-Mann-Whitney $(\mathrm{P} \leq 0,05)$.

\section{RESULTADOS E DISCUSSÃO}

Os resultados da urinálise foram semelhantes entre os grupos em todos os parâmetros analisados, à exceção da presença de proteínas, que apresentaram uma leve tendência à redução no GTE (Tab. 1). Na Fig. 1-A, é observado um desenvolvimento ponderal, esperado para a espécie, proporcional a sua idade, sem apresentar diferenças entre os grupos nas semanas iniciais de acompanhamento; no entanto, a partir da terceira semana de GMI, os animais do GTE apresentaram seu desenvolvimento ponderal aumentado em relação aos demais grupos, e essa diferença se manteve na quarta e quinta semanas de estudo nas GMI. Quando se observa a ingestão sólida (Fig. 1-B), os animais apresentaram um consumo semelhante entre os grupos durante todo o período de estudo.

Tabela 1. Análise física, química e microscópica da urina (urinálise) realizada durante o estudo da gaiola metabólica individual (GMI) de 24 horas $(n=5)$

\begin{tabular}{lllll}
\hline Grupos & GC & GCE & GT & GTE \\
\hline Cor & Amarela & Amarela & Amarela & Amarela \\
Odor & Sui generis & Sui generis & Sui generis & Sui generis \\
Aspecto & Turvo & Turvo & Turvo & Turvo \\
Densidade & 1.043 & 1.041 & 1.035 & 1.047 \\
Depósito & Presente & Presente & Presente & Presente \\
pH & 8 & 8 & 8 & 8 \\
Bilirrubina & Negativo & Negativo & Negativo & Negativo \\
Corpos cetônicos & Negativo & Negativo & Negativo & Negativo \\
Glicose & Negativo & Negativo & Negativo & Negativo \\
Nitritos & Negativo & Negativo & Negativo & Negativo \\
Proteínas & 2 & 2 & 2 & 1 \\
Sangue & Negativo & Negativo & Negativo & Negativo \\
Urobilinogênio & Normal & Normal & Normal & Normal \\
\hline
\end{tabular}



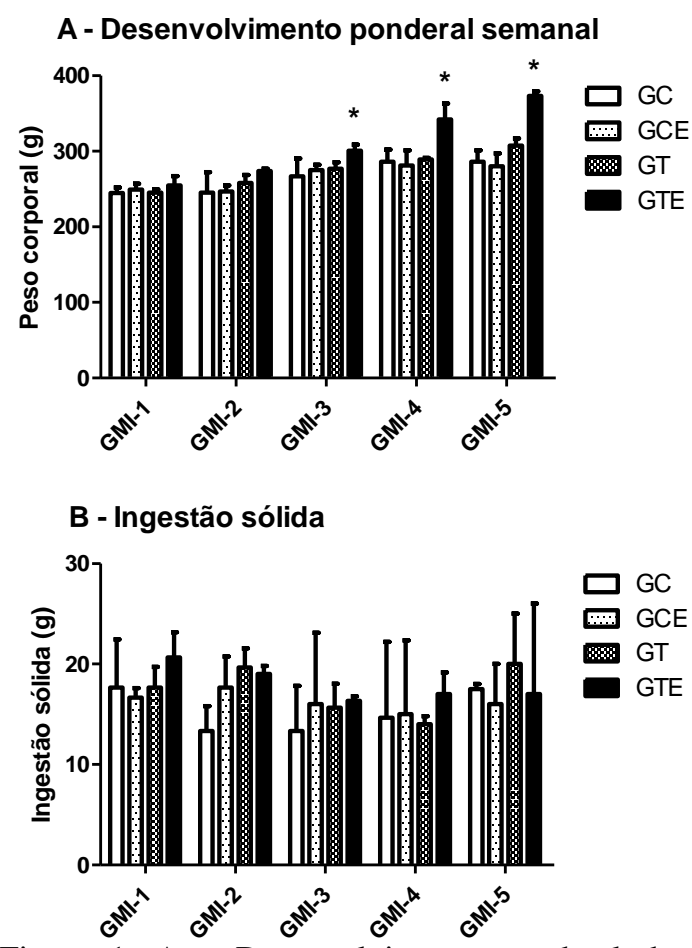

Figura 1. A - Desenvolvimento ponderal dos animais (g) ao longo do estudo da gaiola metabólica individual (GMI). Média \pm desviopadrão; B - ingestão sólida, em 24 horas, expressa em (g), durante o estudo da gaiola metabólica individual (GMI).

A Fig. 2-A apresenta valores de ingestão líquida e volume urinário dos animais nas GMI, onde os animais apresentaram um padrão de consumo de água fornecida compatível com os padrões para a espécie, em todo o período estudado e por todos os grupos experimentais. O consumo de ração e a ingestão hídrica para ratos são, respectivamente, de $5 \mathrm{~g}$ e $10 \mathrm{~mL}$ para cada $100 \mathrm{~g}$ de peso do animal/dia, existindo ainda forte correlação entre consumo de alimento e água ingerida, ou seja, quanto mais alimento é consumido, mais água é ingerida. Contudo, o consumo varia de acordo com a temperatura e umidade ambiental, o estado de saúde, a vida sexual e a hora do dia, tendo os ratos hábitos noturnos e, portanto, alimentandose sempre à noite (Carvalho et al., 2009). A Fig. 2-B apresenta a excreção urinária desses animais. Excetuando-se o GTE na quinta semana de estudos em GMI, que apresentou aumento no seu volume urinário, todos os demais grupos e em todas as semanas de estudos apresentaram volume urinário semelhante. Quanto aos parâmetros hematológicos, não foram observadas alterações significativas nas hemácias, na hemoglobina, no hematócrito, no volume corpuscular médio (VCM) e na concentração de hemoglobina corpuscular média (CHCM) nos grupos experimentais em relação ao seu controle. Houve uma diminuição dos leucócitos no GTE em relação aos grupos GT e GCE.

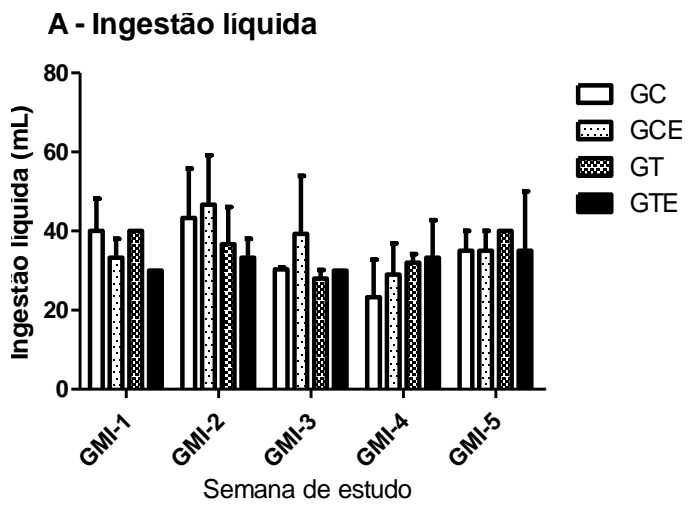

\section{B - Volume urinário}

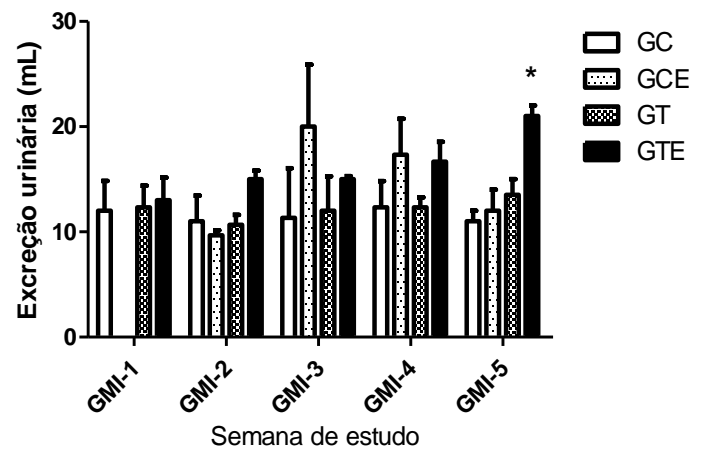

Figura 2. A - Ingestão líquida em 24 horas dos ratos ao longo do estudo da gaiola metabólica individual (GMI); B - volume urinário em 24 horas nos ratos, ao longo do estudo da gaiola metabólica individual (GMI), expresso em mL.

As análises revelaram que, em relação aos linfócitos, houve um aumento no GT e uma diminuição no GTE e, em relação ao número de plaquetas, houve diminuição no GTE quando comparado ao GT e ao GCE. Quanto ao número de proteínas totais, houve diminuição no grupo GTE em comparação aos outros grupos (Tab. 2). De acordo com Cunha et al. (2004), alterações hematológicas, decorrentes do abuso de EAA, também podem ser observadas, como mudanças do tempo de coagulação. Os EAA estimulam a eritropoiese por meio do aumento da síntese de eritropoetina, podendo causar policitemia $\mathrm{e}$ aumento do hematócrito, o que pode favorecer a formação de trombos e aumentar os riscos de 
ocorrência de acidente vascular cerebral isquêmico. Injeções suprafisiológicas EAA tendem a provocar alterações no perfil das lipoproteínas somente após sete semanas de administração (Cunha et al., 2005). Sabe-se geralmente que o abuso de EAA leva a elevados níveis de hematócrito e hemoglobina, como já foi demonstrado em fisiculturistas, de acordo com Mullen et al. (2014), o que não foi o caso dos resultados obtidos neste estudo.

Tabela 2. ${ }^{1}$ Média e desvio-padrão dos hemogramas realizados com ratos tratados com estanozolol $(\mathrm{n}=5)$

\begin{tabular}{lllll}
\hline Grupos & GC & GCE & GT & GTE \\
\hline HE $(\times 106 / \mu \mathrm{L})$ & $7,68 \pm 0,33$ & $7,78 \pm 0,45$ & $7,35 \pm 0,32$ & $7,50 \pm 0,24$ \\
HB $(\mathrm{g} / \mathrm{dL})$ & $16,62 \pm 0,67$ & $16,84 \pm 1,00$ & $16,07 \pm 0,61$ & $16,20 \pm 0,53$ \\
$\mathrm{Ht}(\%)$ & $50,00 \pm 2,00$ & $50,60 \pm 2,94$ & $48,00 \pm 2,12$ & $48,75 \pm 1,64$ \\
VCM $(\mathrm{FL})$ & $65,06 \pm 0,27$ & $65,02 \pm 0,15$ & $65,25 \pm 0,32$ & $64,95 \pm 0,22$ \\
CHCM $(\mathrm{g} / \mathrm{dL})$ & $33,22 \pm 0,07$ & $33,28 \pm 0,04$ & $33,50 \pm 0,35$ & $33,22 \pm 0,04$ \\
Leucócitos $(\mu \mathrm{L})$ & $6.800 \pm 1,63$ & $7.480 \pm 2,03$ & $7.175 \pm 1,18$ & $6.025 \pm 1,79 *$ \\
Linfócitos $(\%)$ & $66 \% \pm 0,05$ & $64 \% \pm 0,10$ & $73 \% \pm 0,06^{*}$ & $60 \% \pm 0,09^{*}$ \\
Plaquetas $(\mu \mathrm{L})$ & $487,10 \pm 65,20$ & $556.560 \pm 44.57$ & $592.150 \pm 60.55$ & $478.525 \pm 77,02^{*}$ \\
Proteínas totais $(\mathrm{g} / \mathrm{dL})$ & $7,16 \pm 0,23$ & $7,20 \pm 0,25$ & $7,00 \pm 0,14$ & $6,40 \pm 0,20^{*}$ \\
\hline
\end{tabular}

${ }^{1}$ Médias seguidas por asterisco diferem significativamente do controle $(\mathrm{P}<0,05)$.

Nos animais do GC, foram observados glomérulos com morfologia normal, alguns túbulos contorcidos com células vacuolizadas e material eosinofílico depositado no lúmen dos túbulos coletores (Fig. 3A-B). Os animais do GCE, em relação ao controle, apresentaram congestão glomerular, túbulos contorcidos com material eosinofílico intraluminal, além de hidropisia (Fig. 3C-D). Os animais do GT apresentaram atrofia glomerular e congestão (Fig. 3D-E). Nos animais do GTE, foram observadas hidropsias, alteração na morfologia dos túbulos contorcidos, vacuolização e degeneração celular dos tubos coletores (Fig. 3G-H). Yoshida et al. (1994) observaram a presença de necrose tubular aguda em um homem de 26 anos com grave colestase e hiperbilirrubinemia após o uso de estanozolol, levando à insuficiência renal. Neste estudo, foram observadas alterações histopatológicas renais significativas em animais submetidos a exercício intenso associado ou não ao estanozolol. Esses achados mostram que o treinamento intenso combinado com EAA, como praticado pelos levantadores de peso, pode causar danos nos rins, por promover apoptose de podócitos, levando à formação de glomeruloesclerose (Revai et al., 2003).

A imuno-histoquímica do VEGF-A nos rins dos animais dos grupos GC e GCE revelou forte marcação nas regiões cortical e medular, principalmente nos glomérulos renais e nos túbulos coletores, respectivamente (Fig. 4A-D). Entretanto, os rins dos animais dos grupos GT e GTE apresentaram fraca marcação para a expressão do VEGF-A (64E-H). A quantificação em pixels da expressão do fator VEGF-A revelou que os grupos GT e GTE apresentaram os menores valores, diferindo significativamente dos demais grupos (Fig. 5). O VEGF-A é considerado o principal fator de crescimento envolvido na angiogênese, e sua expressão é iniciada pela hipóxia e fortemente estimulada pelo estresse de cisalhamento decorrente do aumento do fluxo sanguíneo durante o treinamento aeróbio (Prior et al., 2003, 2004). Além disso, tem função na manutenção das células glomerulares endoteliais, aumentando em resposta à hipertensão e à ativação do sistema renina-angiogensina, mostrando, assim, um papel protetor em condições vasculares estressantes (Advani et al., 2007). Contudo, na maioria das lesões glomerulares crônicas, tem-se observado diminuição da expressão do VEGF-A, como nas glomeruloescleroses focal ou global, na amiloidose, na glomerulonefrite e na nefrite lúpica difusa (Schrijvers et al., 2004). Assim, pode-se inferir que o estanozolol parece interferir na expressão do VEGF-A. 

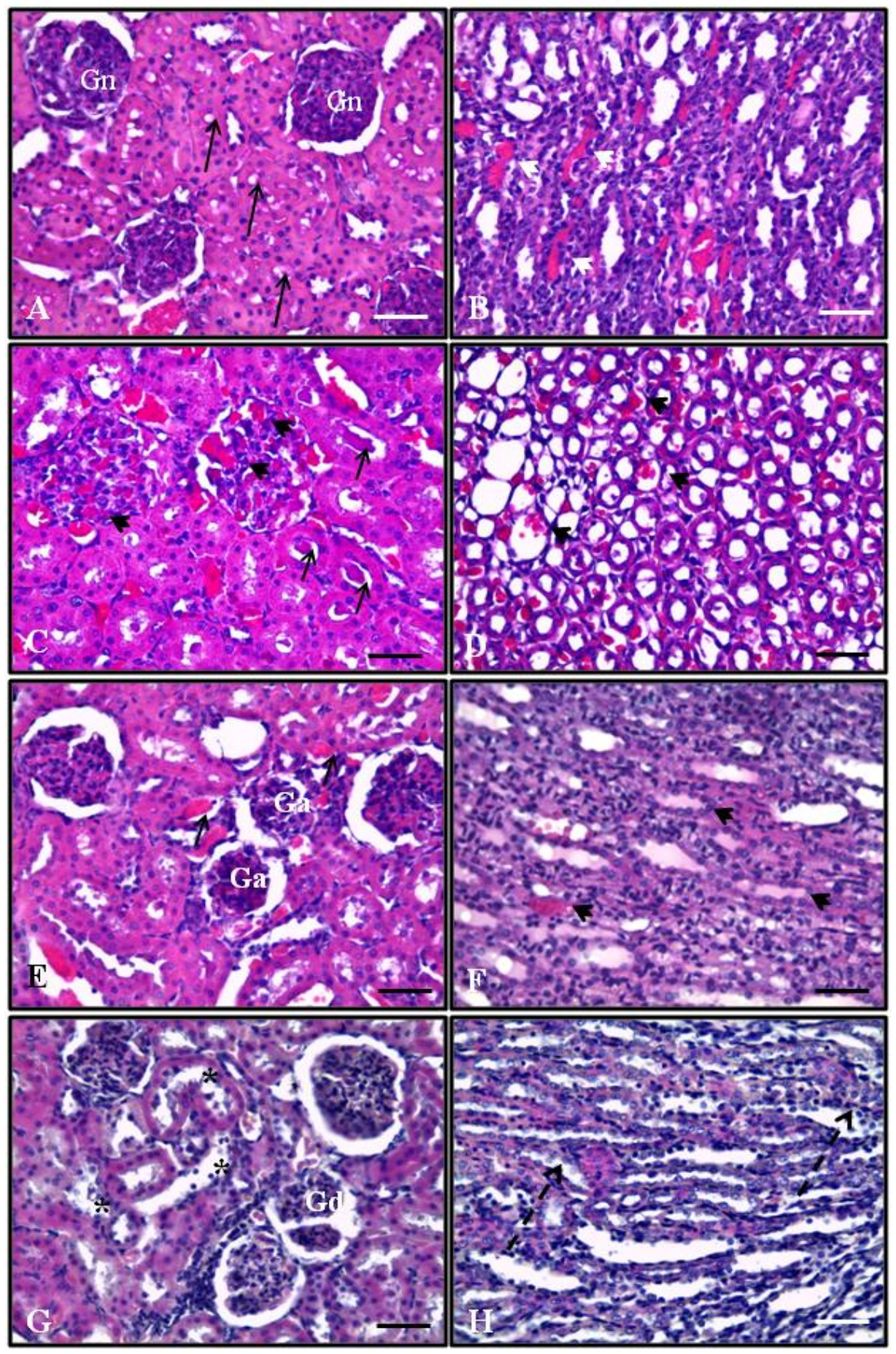

Figura 3. Rins dos animais dos grupos GC (A-B), GCE (C-D), GT (E-F) e GTE (G-H). (A-B): notar glomérulos normais $(\mathrm{Gn})$, túbulo contorcido proximal com presença de alguns vacúolos (setas longas) e congestão discreta na região medular (ponta de setas); (C-D): notar congestão glomerular (ponta de setas), túbulos renais com presença de material eosinofílico intraluminal (setas curtas) e congestão na região medular (ponta de setas); (E-F): notar glomérulos atrofiados (Ga), túbulo contorcido proximal com presença de material eosinofílico intraluminal (setas curtas) e congestão na região medular (ponta de setas); (G-H): notar degeneração dos glomérulos (Gd), túbulos renais com morfologia alterada

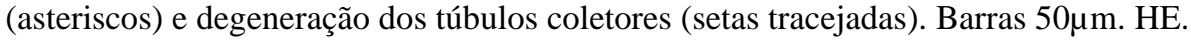




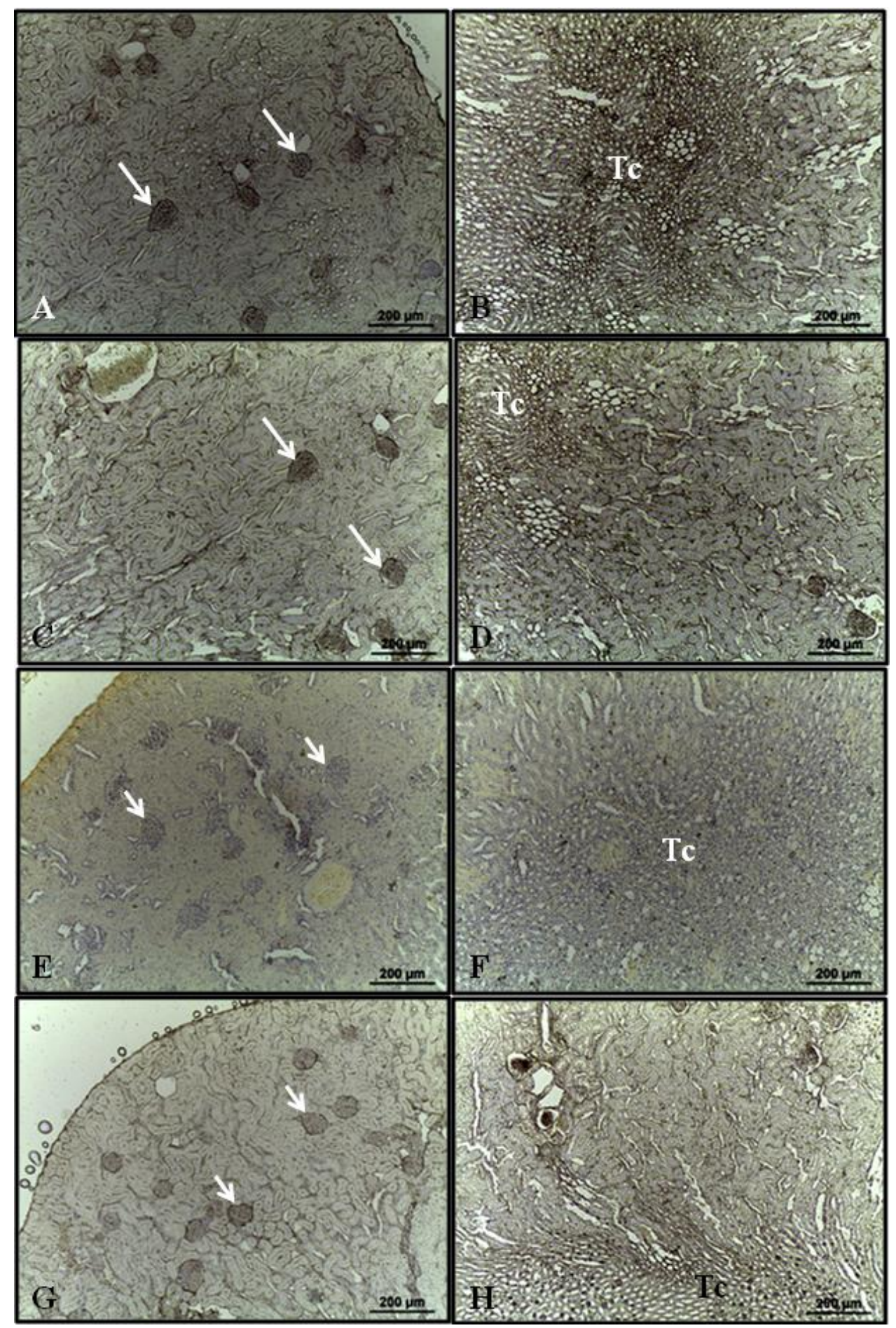

Figura 4. Imuno-histoquímica para o VEGF-A nos rins dos animais dos grupos GC (A-B), GCE (C-D), GT (E-F) e GTE (G-H). (A-B): observar forte marcação nos glomérulos renais (setas longas) e entre os tubos coletores (Tc); (C-D): observar também forte marcação nos glomérulos renais (setas longas) e entre os tubos coletores (Tc); (E-F) e (G-H): observar fraca marcação nos glomérulos renais (setas curtas) e entre os tubos coletores (Tc). 


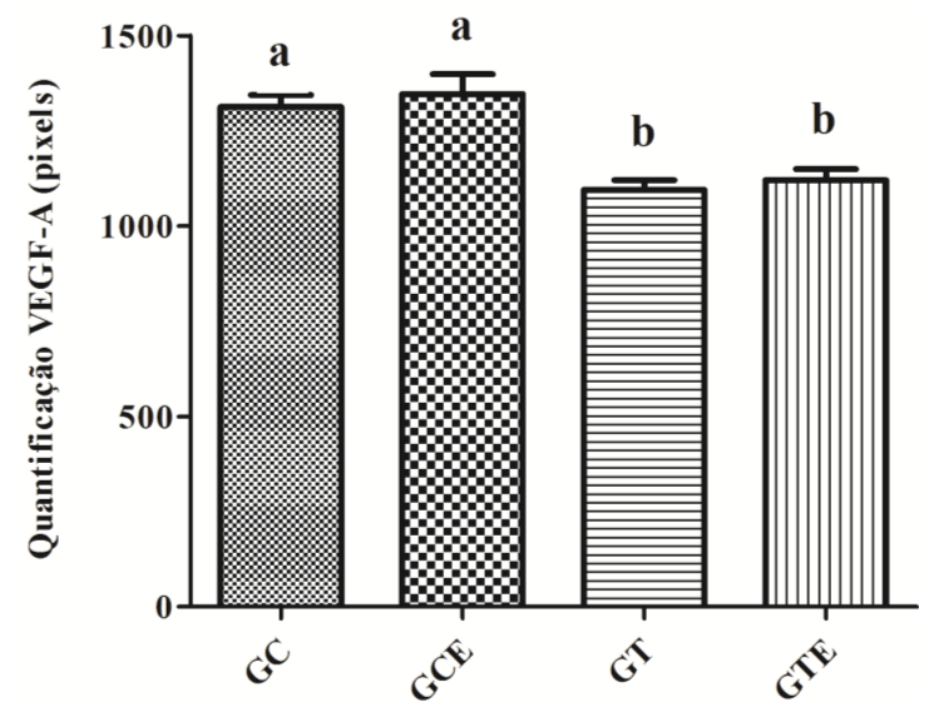

Figura 5. Quantificação em pixels da expressão do fator VEGF-A. Notar redução significativa entre os grupos tratamento (GT) e tratamento exercício (GTE) em relação aos outros. *Médias seguidas pela mesma letra não diferem significativamente entre si pelo teste de Kruskal-Wallis com post-hoc WilcoxonMann-Whitney $(\mathrm{P}<0,05)$.

A quantificação de glicogênio hepático revelou redução significativa nos grupos GCE, GT e GTE em relação ao controle, porém os dois últimos grupos apresentaram os menores valores, sem, no entanto, diferirem entre si (Fig. 6). Esse efeito parece ser mais fortemente associado ao uso do anabolizante do que ao fator intensidade de treino, sobretudo porque os grupos que fizeram uso do estanozolol apresentaram os menores valores, o que pode estar relacionado a uma interferência na gliconeogênese hepática (Frankenfeld et al., 2014). A histopatologia do fígado revelou, nos animais do grupo GC, parênquima hepático, espaço porta e sinusoides bem

(Fig. 7A).

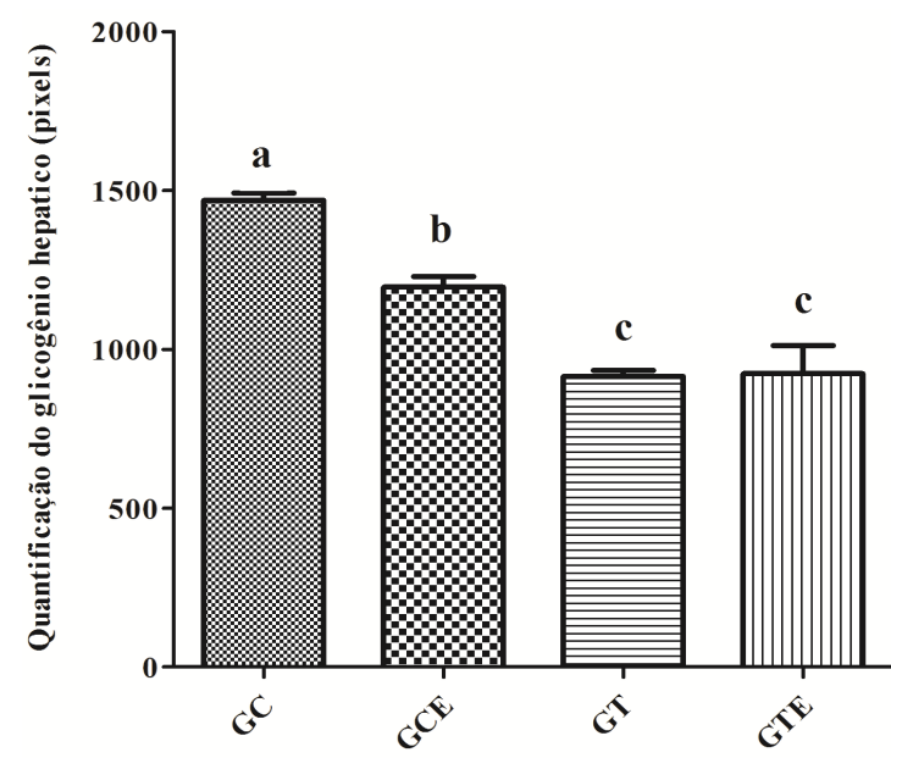

Figura 6. Quantificação de glicogênio pelo método PAS. *Médias seguidas pela mesma letra não diferem significativamente entre si pelo teste de Kruskal-Wallis com post-hoc Wilcoxon-Mann-Whitney $(\mathrm{P}<0,05)$. 


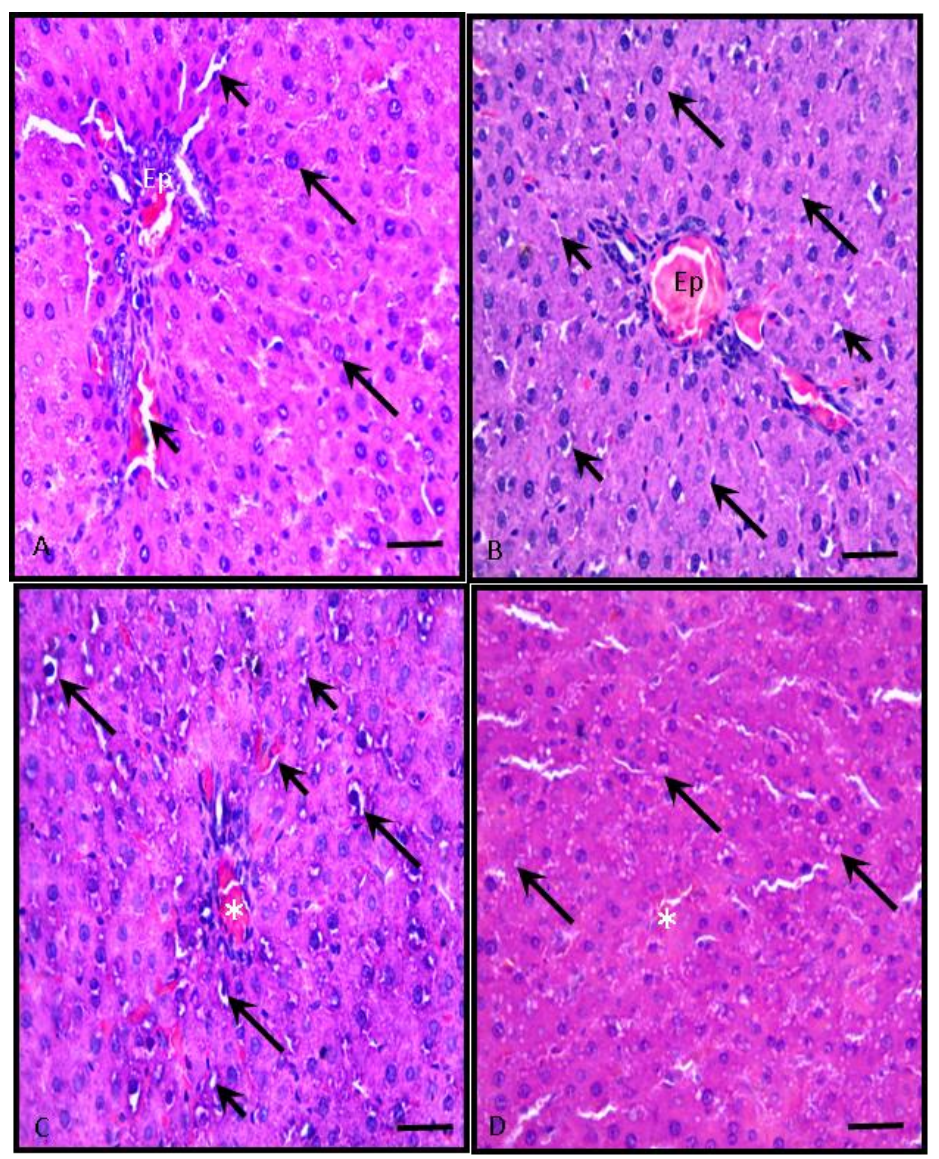

Figura 7. Fígado dos animais dos grupos GC (A), GCE (B), GT (C) e GTE (D). A: observar parênquima hepático com cordões de hepatócitos (setas longas), espaço porta (Ep) e sinusoides (setas curtas) bem preservados; B: observar hepatócitos hipertróficos (setas longas) e redução do espaço do capilar sinusoide (setas curtas); C e D: observar congestão de veia hepática (asterisco), vacuolização dos hepatócitos (setas longas) e atrofia dos capilares sinusoides e). Barras 50 $\mu \mathrm{m}$. HE.

No fígado dos animais do GCE, evidenciaram-se hepatócitos hipertróficos diminuindo o lúmen dos sinusoides (Fig. 7B). Nos grupos GT e GTE, houve congestão da veia hepática, vacuolização moderada dos hepatócitos, atrofia dos capilares sinusoides e proliferação dos ductos biliares (Fig. 7C-D). Segundo Cruzat et al. (2007), indivíduos que se submetem a exercícios intensos e prolongados ou a treinos exaustivos, ou, ainda, que possuem frequência de treinamento muito elevada podem promover processo inflamatório local e estresse oxidativo. Isso poderia explicar as alterações hepáticas apresentadas pelos animais do grupo GCE. De acordo com Neri et al. (2011), estanozolol, bem como outros EAA ativos administrados por via oral, tem demonstrado causar lesões inflamatórias ou degenerativas nos hepatócitos centrilobulares, alterações ultraestruturais nos canalículos e alterações degenerativas em mitocôndrias e lisossomos.

\section{CONCLUSÃO}

O presente estudo demonstra que a administração de estanozolol, na dose de $5,0 \mathrm{mg} / \mathrm{kg}$, em ratos Wistar, causa alterações na morfologia renal e hepática, podendo levar à falência dos rins e do fígado.

\section{REFERÊNCIAS}

ADVANI, A.; KELLY, D.J.; ADVANI, S.L. et al. Role of VEGF in maintaining renal structure and function under normotensive and hypertensive conditions. Proc. Natl. Acad. Sci. USA, v.104, p.14448-14453, 2007. 
BAHRKE, M.S.; YESALIS, C.E.; Abuse of anabolic androgenic steroids and related substances in sport and exercise. Curr. Opin. Pharmacol., v.4, p.614-620, 2004.

BOCALINE, D.S.; BEUTEL, A. Treadmill exercise training prevents myocardial mechanical dysfunction induced by androgenic- anabolic steroid treatment in rats. PLoS One, p.e87106, 2014.

BREUER, M.E., Y.; McGINNIS, M.Y.; LUMIA, A.R., POSSIDENTE, B.P. Aggression in male rats receiving anabolic androgenic ateroids: effects of social and environmental provocation. Hormones and behavior, v.40, Issue 3, p.409-418, 2001.

CARVALHO, G.B.; MASSENO, A.P.B.; ZANINI, M.S. et al. Avaliação clínica de ratos de laboratório (Rattus novergicus linhagem Wistar): parâmetros sanitários, biológicos e fisiológicos. Rev. Ceres, v.56, p.51-57, 2009.

CRUZAT, V.F.; ROGERO, M.M.; BORGES, M.C.; TIRAPEGUI, J. Aspectos atuais sobre estresse oxidativo, exercícios físicos e suplementação. Rev. Bras. Med. Esporte, v.13, p.336-342, 2007.

CUNHA, T.S.; CUNHA, N.S.; MOURA, M.J.C.S.; MARCONDES, F.K. Esteroides anabólicos androgênicos e sua relação com a prática desportiva. Rev. Bras. Ciênc. Farmac., v.40, p.165-179, 2004.

CUNHA, T.S.; TANNO, A.P.; MOURA, M.J.C.S.; MARCONDES, F.K. Influence of high-intensity exercise training and anabolic androgenic steroid treatment on rat tissue glycogen content. Life Sci. v.77, p.1030-1043, 2005.

D'ERRICO, S.; DI BATTISTA, B. Renal heat shock proteins over expression due to anabolic androgenic steroids abuse. Mini Rev. Med. Chem., v.11, p.446450, 2011.

FRANKENFELD, S.P.; OLIVEIRA, L.P.; IGNACIO, D.L.; COELHO, R.G. et al. Nandrolone decanoate inhibits gluconeogenesis and decreases fasting glucose in Wistar male rats. J. Endocrinol., v.220, p.143-153, 2014.

LISE, M.L.Z.; GAMA E SILVA, T.S.; FERIGOLO, M.; BARROS, H.M.T. O abuso de esteróides anabólico-androgênicos em atletismo. Rev. Assist. Méd. Bras., v.45, p.364-370, 1999.

MULLEN, J.E.; GÅREVIK, N.; SCHULZE, J.J. et al. Perturbation of the Hematopoietic Profile by Anabolic Androgenic Steroids. J. Horm., v.2014, 2014. Disponível em: <https://doi.org/10.1155/2014/510257>. Acessado em: 5 jun. 2019.
NERI, M.; BONSIGNORE, A. Anabolic androgenic steroids abuse and liver toxicity. Mini Rev. Med. Chem., v.11, p.430-437, 2011.

OBERHOLZER, M.; OSTREICHER, M., CHRISTEN, H.; BRUHLMANN, M. Methods in quantitative image analysis. Histochemistry and cell biology, 1996.

PEY, A.; SABORIDO, A.; BLÁZQUEZ, I.; DELGADO, J.; MEGÍAS, A. Effects of prolonged stanozolol treatment on antioxidant enzymes activities, oxidative stress markers, and heat shock protein HSP72 levels in rat liver. J. Steroid Biochem. Mol. Biol., v.87, p.269-277, 2003.

PRIOR, B.M.; LLOYD, P.G.; YANG, H.T.; TERJUNG, R.L. Exercise-induced vascular remodeling. Exerc. Sport Sci. Rev., v.31, p.26-33, 2003

PRIOR, B.M.; YANG, H.T.; TERJUNG, R.L. What makes vessels grow with exercise training? J. Appl. Physiol., v.97, p.1119-1128, 2004.

REVAI, T.; SÁPI, Z.; BENEDEK, S.; KOVÁCS, A.; KASZÁS, I.; VIRÁNYI, M.; WINKLER, G. Severe nephrotic syndrome in a young man taking anabolic steroid and creatine long term. Orv. Hetil. v.49, p.2425-2427, 2003

SCHRIJVERS, B.F.; FLYVBJERG, A.; DE VRIESE, A.S. The role of vascular endothelial growth factor (VEGF) in renal pathophysiology. Kidney Int., v.65, p.2003-2017, 2004.

TÖLGYESI, Á.; SHARMA, V.K. Confirmatory analysis of stanozolol metabolites in bovine, pig and sheep urines using an optimized clean-up and liquid chromatography-tandem mass spectrometry. $J$. Pharm. Biomed. Anal., v.88, p.45-52, 2014.

TUFRO, A. VEGF spatially directs angiogenesis during metanephric development in vitro. Dev. Biol., v.227, p.558-566, 2000

WELDER, A. A. Toxic effects of anabolic-androgenic steroids in primary rat hepatic cell cultures. $J$. Pharmacol. Toxicol. Methods, v.33, p.187-195, 1995.

YOSHIDA, E.M.; KARIM, M.A.; SHAIKH, J.F. et al. At what price, glory? Severe cholestasis and acute renal failure in an athlete abusing stanozolol. Can. Med. Assoc. J., v.151, p.791-793, 1994. 